\title{
Statistical Analysis of the Combined ECAP and Heat Treatment for Recycling Aluminum Chips Without Remelting
}

\author{
Jure Krolo ${ }^{1, *(D)}$, Branimir Lela ${ }^{1}$, Ivana Dumanić ${ }^{1}$ and Franjo Kozina ${ }^{2}$ \\ 1 Faculty of Electrical Engineering, Mechanical Engineering and Naval Architecture, University of Split, \\ 21000 Split, Ruđera Boškovića 32, Croatia; blela@fesb.hr (B.L.); iduman00@fesb.hr (I.D.) \\ 2 Faculty of Metallurgy, University of Zagreb, 44000 Sisak, Aleja Narodnih Heroja 3, Croatia; fkozin@simet.hr \\ * Correspondence: jkrolo@fesb.hr; Tel.: +385-(0)-21305-631
}

Received: 22 May 2019; Accepted: 4 June 2019; Published: 6 June 2019

check for updates

\begin{abstract}
The main aim of this paper is to present an environmentally friendly method for aluminum recycling. Development of new recycling technologies in order to increase scrap reuse potential and $\mathrm{CO}_{2}$ emission savings are of the main importance for aluminum circular economy. In this paper, aluminum chips waste was recycled without any remelting phase in order to increase energy and material savings. The presented process is usually called solid state recycling or direct recycling. Solid state recycling process consists of chips cleaning, cold pre-compaction and hot direct extrusion followed by a combination of equal channel angular pressing (ECAP) and heat treatment. Influence of holding time during solid solution treatment and both artificial aging time and temperature on mechanical properties of the recycled EN AW 6082 aluminum chips were investigated. A comprehensive number of the experiments were performed utilizing design of experiments approach and response surface methodology. Regression models were developed for describe the influence of heat treatment parameters for presented solid state recycling process on mechanical properties of the recycled samples. Utilizing novel procedure high quality recycled samples were obtained with mechanical properties comparable with commercially produced EN AW 6082 aluminum alloy in T6 temper condition. Metallographic analysis of the recycled samples was also performed.
\end{abstract}

Keywords: solid state recycling; aluminum; regression analysis; ECAP; heat treatment

\section{Introduction}

Aluminum is the second most used metal on earth and recyclability of aluminum is a fundamental quality of this light metal. Aluminum primary production from ore resources requires very high energy consumption of $157 \mathrm{GJ} / \mathrm{t}$ for the European Union industry. However, during the recycling process energy consumption is only $7.85 \mathrm{GJ}$ to produce one tonne of recycled or so-called secondary aluminum (this value strongly depends on input scrap type and furnace technology) [1]. Despite a 95\% lower energy consumption, constant improvements in aluminum recycling technologies and strategies are necessary. According to the International Aluminum Institute (IAI), aluminum consumption on a global level is constantly increasing. Projections from 2015-2050 predict that demand for aluminum will be doubled [2,3]. Furthermore, according to the Intergovernmental Panel on Climate Change (IPCC) most of the observed increase in globally averaged temperatures is very likely due to the increase in anthropogenic greenhouse gas concentration. Therefore, in order to limit the global average temperature increase to $2.0-2.4{ }^{\circ} \mathrm{C}$ and reduce the negative impact on the environment, IPCC recommends that global emission of the greenhouse gases into the atmosphere should be reduced by 50-80\% compared to the emissions levels in the 1990s [4]. 
In order to reduce the negative effect on the environment, various authors recognized solid state recycling (SSR) as a possible alternative to the conventional aluminum recycling process [4-9]. When SSR is employed, material losses are much smaller because the remelting phase is completely avoided. Aluminum is a highly reactive material and it has a tendency to form aluminum oxide on its surface. This is even more pronounced for lightweight aluminum scrap due to its high surface to mass ratio. During the remelting process this oxide is floating on the melt surface mixed with dross. Therefore, aluminum lightweight scrap (chips, foils, and sheet skeletons) is problematic when conventional recycling technology is used because up to $20 \%$ of the aluminum can be lost due to the mixing with dross and burning [9]. According to previous research papers concerned with SSR process, it is possible for material yield to be over $90 \%$ when this type of recycling is employed, while energy consumption can be only 10\% compared to conventional recycling process that uses remelting [6-8]. Furthermore, manufacturing profiles from solid state bonded chips gives a $96 \%$ saving in $\mathrm{CO}_{2}$ emission compared to production from billets made by conventional recycling of aluminum manufacturing waste [8]. In order to produce SSR samples with appropriate quality, the combination of the high temperature, normal stress, shear stress, and plastic deformation should be achieved [6,7]. Therefore, the most used process for SSR is direct hot extrusion, but lately severe plastic deformation (SPD) processes opened new possibilities [10]. SPD is usually used to produce materials with a fine grain structure. A finer grain size increases the strength and the fracture toughness of the material [11]. SPD processes commonly used for SSR are: Equal channel angular pressing (ECAP) [12,13], cyclic extrusion compression (CEC) [14], and high pressure torsion (HPT) [15]. Lately, new and promising methods for SSR are arising such as friction stir extrusion (FSE) [16] and friction stir consolidation (FSC) [17]. Tang et al. [16] utilized FSE to produce aluminum AW 2050 and AW 2195 defect free wires from the machining chips, with good combination of the microhardness and bend ductility. There were only a few papers where combination of extrusion and ECAP process was investigated. Ying et al. [18] investigated solid state recycling of AZ91 Mg alloy utilizing combination of the hot extrusion and afterwards one ECAP pass on $300^{\circ} \mathrm{C}$. After ECAP on elevated temperatures, crystal grains were refined inside recycled specimens. Furthermore, interfaces of the chips disappear after extrusion and after ECAP, which indicates the improvement of the bonding between chips [18]. Krolo et al. [19] utilized a combination of the direct hot extrusion and ECAP at different temperatures to investigate the influence of SSR process parameters on recycled samples microhardness and electrical conductivity. According to this research the lower extrusion temperature and extrusion ratio could be used to obtain quality SSR samples if afterwards only one ECAP pass will be applied [19]. Hasse et al. [20] integrated ECAP die into conventional hot extrusion process for quality SSR samples production.

In this paper, novel SSR process was presented for the production of the high-quality recycled samples. The process consisted of direct hot extrusion followed by a combination of equal channel angular pressing and heat treatment. First, ECAP pass was performed on room temperature, immediately after direct hot extrusion and extrudate cooling in the air. Secondly, ECAP pass was performed after samples solid solution treatment and quenching into water. Prior to a second ECAP pass, samples were rotated by $180^{\circ}$ in order to achieve homogeneous microstructure. In order to produce metals with advanced mechanical and technological properties, the combination of the SPD and heat treatment was lately investigated [21,22]. Utilizing the same approach, the main aim of this paper, was to produce high quality SSR samples. SPD should assist in grain refinement and fracture of the oxide layers, naturally created on aluminum chips surface, which should lead to the improved chips bonding. Heat treatment should improve the interparticle chip diffusion, while prolonged heating duration to a certain extent can cause better homogeneity of the SSR samples microstructure [23].

Furthermore, according to the previous researches, a detailed description of the influence of heat treatment parameters on SSR samples for the presented process is still missing. Therefore, in order to describe the influence of the heat treatment parameters (solid solution time, artificial aging time, and temperature) on recycled samples mechanical properties, statistical approach was used. The main aim of the statistical analysis is to create mathematical models which are able to describe and to predict the 
influence of heat treatment parameters on mechanical properties of the obtained samples. Obtained models should serve as a valuable tool in novel recycling process investigation. In order to do statistical analysis, 20 experiments were performed according to the experimental plan. From an available literature review, there were only a few papers where authors used a similar statistical approach to describe SSR process for some other methods than presented here [19,24-26]. Therefore, there is a lack of mathematical description of SSR processes.

\section{Design of Experiments}

Design of experiments (DOE) and response surface methodology (RSM) were used for SSR process description. Authors decided to use this approach in order to describe the influence of heat treatment parameters on mechanical properties of SSR samples for presented SSR process. Due to the complex material behavior during SSR and multiple different influences on recycled material such as intensive plastic deformation, grain refinement, material solid bonding, interparticle diffusion, and heat treatment, the statistical description should provide more detailed insight on mechanical properties of the recycled samples. The main aim of this statistical approach is to create mathematical models which are capable to describe and to predict recycled samples mechanical properties (ultimate tensile strength- $R m$, yield strength- $R p_{0.2}$, and percentage elongation- $P E$ ) in regard to the selected heat treatment parameters. D-Optimal experimental design was selected. In the experimental research and modeling D-Optimal design is often used because it offers some advantages compared to other response surface methods like optimization possibility and reduction of the number of experiments [27]. Design Expert software package was used for DOE and 20 experiment points were designed in stochastic order. This was an important step because regression and variance analysis of obtained results were performed. Three selected numerical factors where holding time on solid solution temperature and both artificial aging temperature and time. Heat treatment parameters for SSR process were selected according to the results from the above-mentioned researches [21,22]. Solid solution time was varied in a range from 60-180 min. Artificial aging temperature was varied in a range from $100-200{ }^{\circ} \mathrm{C}$ and finally artificial aging time vas varied in range from 1-8 h. Selected heat treatment parameters and tensile testing results for all 20 experimental points are provided in Table 1.

Table 1. Experimental points according to D-Optimal design with tensile testing results for solid state recycled aluminum alloy EN AW 6082.

\begin{tabular}{ccccccc}
\hline $\begin{array}{c}\text { Levels of } \\
\text { Exp. Runs }\end{array}$ & $\begin{array}{c}\text { Solid Solution } \\
\text { Time }\left({ }^{\circ} \mathbf{C}\right)\end{array}$ & $\begin{array}{c}\text { Artificial Aging } \\
\text { Temperature }\left({ }^{\circ} \mathbf{C}\right)\end{array}$ & $\begin{array}{c}\text { Artificial Aging } \\
\text { Time }(\mathbf{m i n})\end{array}$ & $\boldsymbol{R m} \mathbf{( M P a )}$ & $\begin{array}{c}\boldsymbol{R} \boldsymbol{p}_{\mathbf{0 . 2}} \\
\mathbf{( M P a})\end{array}$ & $\boldsymbol{P E ( \% )}$ \\
\hline 1 & 106.9 & 200.0 & 3.53 & 286 & 266 & 8.2 \\
2 & 60.0 & 200.0 & 8.00 & 248 & 226 & 9.6 \\
3 & 105.0 & 155.1 & 1.11 & 362 & 326 & 10.5 \\
4 & 180.0 & 200.0 & 2.43 & 292 & 278 & 9.2 \\
5 & 115.2 & 154.1 & 5.16 & 336 & 320 & 8.8 \\
6 & 105.0 & 100.0 & 5.26 & 349 & 318 & 10.2 \\
7 & 180.0 & 100.0 & 5.94 & 322 & 289 & 10.8 \\
8 & 60.0 & 200.0 & 1.00 & 300 & 292 & 7.2 \\
9 & 180.0 & 100.0 & 5.94 & 334 & 296 & 10.8 \\
10 & 180.0 & 200.0 & 8.00 & 264 & 240 & 11.2 \\
11 & 128.3 & 100.0 & 1.00 & 308 & 288 & 8 \\
12 & 60.0 & 150.0 & 6.79 & 330 & 312 & 8.6 \\
13 & 60.0 & 200.0 & 1.00 & 318 & 307 & 9.8 \\
14 & 180.0 & 200.0 & 8.00 & 256 & 232 & 9.8 \\
15 & 60.0 & 100.0 & 8.00 & 328 & 296 & 9.9 \\
16 & 120.0 & 198.5 & 7.06 & 259 & 234 & 11.5 \\
17 & 60.0 & 100.0 & 2.45 & 314 & 286 & 9.5 \\
18 & 180.0 & 143.0 & 1.00 & 328 & 293 & 11.9 \\
19 & 60.0 & 100.0 & 8.00 & 320 & 288 & 9.7 \\
20 & 60.0 & 100.0 & 2.45 & 317 & 298 & 7.1 \\
\hline
\end{tabular}




\section{Materials and Methods}

\subsection{Machining Chips Fabrication and Cold Compaction}

Aluminum waste in form of the machining chips was obtained from the turning process, Figure 1a. Selected aluminum alloy for SSR process was EN AW 6082 extruded bar in T6 temper condition due to the wide application of this alloy in the machining processes. Furthermore, authors noticed there were only a few papers that mentioned the possibility of the solid state recycling for this specific alloy $[19,28,29]$. Chemical composition of the selected aluminum alloy was provided according to the EN-573-3 standard in Table 2.
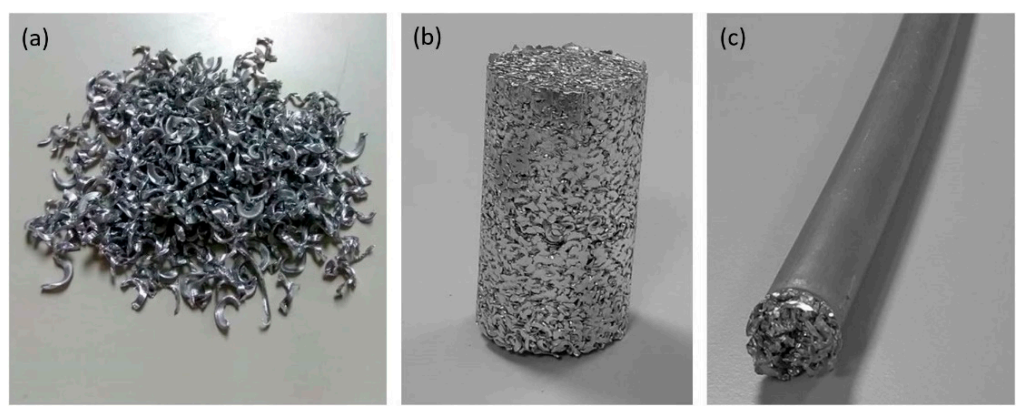

Figure 1. Material formation during solid state recycling (SSR) process: (a) aluminum chips (b) chips-based billet (c) extruded bar.

Table 2. Chemical composition of aluminum alloy EN AW 6082.

\begin{tabular}{cccccccccc}
\hline Element & $\mathbf{S i} \%$ & $\mathrm{Fe} \%$ & $\mathrm{Cu} \%$ & $\mathrm{Mn} \%$ & $\mathrm{Mg} \%$ & $\mathrm{Zn} \%$ & $\mathrm{Ti} \%$ & $\mathrm{Cr} \%$ & $\mathrm{Others} \%$ \\
\hline Min.-Max. & $0.7-1.3$ & $0-0.5$ & $0-0.1$ & $0.4-0.1$ & $0.6-1.2$ & $0-0.2$ & $0-0.1$ & $0-0.25$ & $0-0.15$ \\
\hline
\end{tabular}

In order to avoid contamination with cooling and lubrication fluid, dry turning process was performed on a universal lathe "Prvomajska" D-420/1500 (Prvomajska, Raša, Croatia) using an Iscar tool composed of the tool holder SVJCR 2020 K-16 (Iscar, Tefen, Israel) and the cutting insert VCGT 160404-ASIC20 (Iscar, Tefen, Israel). According to Shamsudin et al. [23], it is important to take care about chips contamination with cooling and lubrication fluid or impurities because all of these would alter chips chemical composition and subsequently impair bonding of the chips which therefore will affect the bonding quality during solid state recycling. Turning parameters for the fabrication of the aluminum chips and chips average length $\left(l_{\text {avg }}\right)$, thickness $\left(t_{\text {avg }}\right)$, and width $\left(w_{\text {avg }}\right)$ are provided in Table 3. Turning parameters have direct influence on the machined chips geometry. Chips geometry have influence on recycled samples oxide contamination from the chips surface. Furthermore, the chips morphology influences the quality of the chip-based extrudate if insufficient stress and strain are applied during the plastic working [10]. Tekkaya et al. [7] explained that minimum level of stress, strain, and temperature conditions are required to create a sufficient metallic bonding. If these conditions are fulfilled, small amount of the oxide contamination and therefore chips geometry can be neglected [7].

Table 3. Turning parameters for the fabrication of the chips and geometric chip characterization.

\begin{tabular}{cc}
\hline Turning Parameters & Value \\
\hline Cutting speed & $v_{c}=350 \mathrm{~m} / \mathrm{min}$ \\
Feed rate & $f=0.14 \mathrm{~mm} / \mathrm{rev}$ \\
Cutting depth & $a_{p}=0.5 \mathrm{~mm}$ \\
Chip geometry & - \\
Length & $l_{\text {avg }}=10 \mathrm{~mm}$ \\
Width & $w_{\text {avg }}=1.8 \mathrm{~mm}$ \\
Thickness & $t_{\text {avg }}=0.8 \mathrm{~mm}$ \\
\hline
\end{tabular}


The first step in order to perform SSR process was cold compaction of the machining chips. Machining chips were weighted to the same mass of $150 \mathrm{~g}$ and afterwards compacted into billets with $38 \mathrm{~mm}$ in diameter and $67 \mathrm{~mm}$ in height. Three compaction steps were necessary in order to produce final billet due to the high volume reduction. First two compaction steps were performed with $200 \mathrm{kN}$ force, while the final step was performed with $300 \mathrm{kN}$ force. Compaction was performed on a hydraulic press, while the force was measured with HBM load cell C6A 1MN sensor. Previously was showed that cold compaction force does not have any significant influence on SSR samples tensile strength or yield strength [24]. However, compaction force should be sufficient to achieve good billets structure without any chip disintegration or crumble. Furthermore, sufficient relative density for the billet (density of the chips-based billet compared with conventional cast billet density) should be achieved in order to minimize entrapped air or blister in the extruded profile [30], Figure 1b.

\subsection{Direct Hot Extrusion}

Second step was direct hot extrusion of the chips-based billets at $450{ }^{\circ} \mathrm{C}$. Billets were preheated for $20 \mathrm{~min}$ at $460{ }^{\circ} \mathrm{C}$ and direct hot extruded with a 7.1 extrusion ratio. The diameter of extrusion container was $40 \mathrm{~mm}$. In order to produce solid sections out of the compacted billets, a flat die with an orifice diameter of $15 \mathrm{~mm}$ was used. The punch speed was $1 \mathrm{~mm} / \mathrm{s}$. The temperature was controlled using Omron temperature regulator E5CC and Relay G3PE-225B DC12-24 (OMRON (Shanghai) Co., Ltd., Shanghai, China). Extrusion pressure was measured with HBM P15RVA1/500B pressure gauge transducer (Hottinger Baldwin Messtechnik GmbH, Darmstadt, Germany) suitable for measuring static and dynamic pressures of liquids up to 500 bar and extrusion force was calculated utilizing Matlab software package. After hot extrusion, obtained bars with a $15 \mathrm{~mm}$ diameter were cut to have a length of $80 \mathrm{~mm}$. Obtained sections showed good surface without any blistering or cracks and some showed little imperfections, but the overall conclusion was that surface quality was very good for all sections, Figure 1c. At the front end of the samples due to the lack of the pressure at the beginning of the extrusion process bonding of the machining chips was insufficient, and this part was discarded, same as extrusion butt scrap.

\subsection{Combination of ECAP Process and Heat Treatment}

As stated in the previous investigation, small extrusion ratio was not sufficient to obtain high quality SSR samples without any cracks, voids, and porosity $[10,24,31]$. Therefore, in order to improve SSR samples properties obtained with small extrusion ratio, ECAP process was performed. One room temperature ECAP pass after direct hot extrusion with small extrusion ratio, should be sufficient to obtain quality SSR samples [19]. The main purpose of ECAP process was to introduce severe plastic deformation into SSR samples which should lead to improvement of the recycled samples properties. During the ECAP process material is pressed through a die consisting of two intersecting channels with identical cross sections. ECAP is one of the most popular processes for SPD because processed sample keep the same geometrical shape and dimension as prior the process [11]. Furthermore, samples can be processed with ECAP more than once, which increase total plastic strain introduced into samples. In this case SPD contributed not only for grain refinement, but also for additional fracture and refinement of the oxide layers between aluminum chips. Fracture of the oxide layers and their homogeneous distribution inside recycled sample are crucial for high quality SSR samples production [31]. The diameter of the ECAP tool channel used in this work was $15.1 \mathrm{~mm}$. ECAP tool geometry was defined with inner die corner angle value $90^{\circ}$ and outer die corner angle value $12^{\circ}$ (defined with $3 \mathrm{~mm}$ radius). ECAP process was performed at room temperature and two passes were applied in total. However, the first ECAP pass was performed immediately after direct hot extrusion and extrudate cooling on air, while the second ECAP pass was performed after samples solid solution treatment and quenching into water. Solid solution treatment was performed by reheating of the samples on $535^{\circ} \mathrm{C}$ and holding appropriate time according to the experimental plan, Table 1. In order to achieve a semi-continuous process, ECAP was performed by pressing one sample 
on the other one. After first pass samples were rotated by $180^{\circ}$ in order to achieve homogenous microstructure. This is usually called route C [11]. The used lubrication was graphite grease. ECAP pressure was measured with HBM P15RVA1/500B pressure gauge transducer. Punch displacement was measured with WDS-1000-P60-SR-U draw wire sensor (Micro-Epsilon Messtechnik GmbH \& Co. KG, Ortenburg, Germany). Finally, all samples were artificially aged in order to achieve high quality samples comparable with conventional direct hot extruded bar in T6 condition. Artificial aging time and temperature were varied according to the experimental plan, Table 1 . Figure 2 shows innovative solid state recycling process schematic representation.

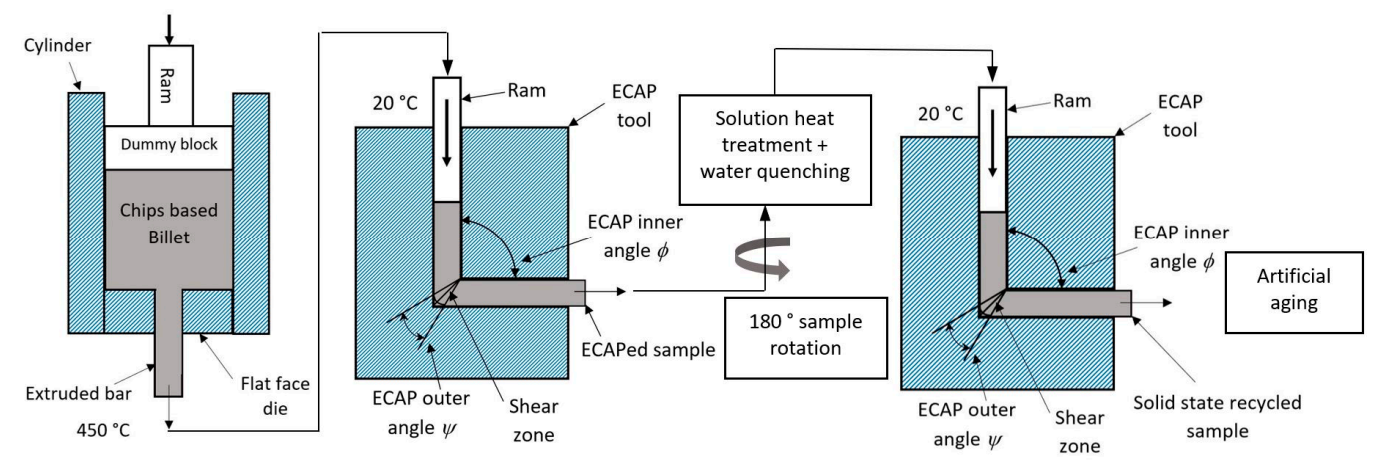

Figure 2. Schematic representation of the solid state recycling process (direct hot extrusion (DE) + equal channel angular pressing (ECAP) + heat treatment).

\section{Results Analysis and Discussion}

\subsection{Tensile Testing Results}

Mechanical testing was performed according to ASTM E8 standard for metallic material tensile testing. The used device was "Instron 8801" $50 \mathrm{kN}$ universal testing machine (Instron, High Wycombe, UK). Tensile specimens were prepared with gauge original length $10 \mathrm{~mm}$, reduced section length $16 \mathrm{~mm}$ and gauge diameter $2.5 \mathrm{~mm}$, Figure 3. Samples were machined from the central part of the recycled samples in order to obtain homogeneous microstructure. Tensile testing was performed at room temperature with the initial strain rate $1.25 \times 10^{-3} \mathrm{~s}^{-1}$.

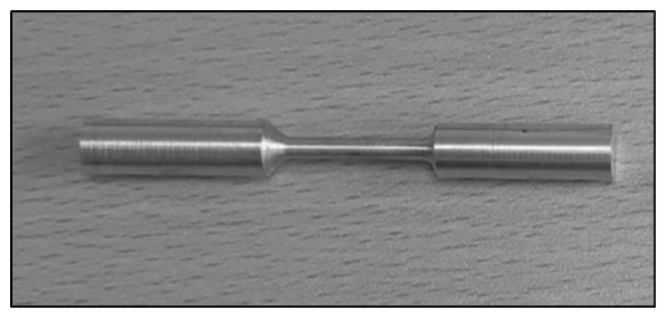

Figure 3. Solid state recycled sample prepared for tensile testing.

According to the tensile testing results and EN 755-2: 2016 standard for aluminum and aluminum alloy extruded bar, all SSR samples have mechanical properties comparable with commercially produced EN AW 6082 extruded bar in T6 condition. According to the EN 755-2: 2016 standard for EN AW 6082 extruded bar in T6 condition with diameter smaller than $20 \mathrm{~mm}$, minimal requirements for tensile strength $(R m)$, yield strength $\left(R p_{0.2}\right)$, and percentage elongation $(P E)$ were $295 \mathrm{MPa}, 250 \mathrm{MPa}$, and $8 \%$, respectively. However, in practice, usually these values for the EN AW 6082 alloy are $R m$ $\sim 340 \mathrm{MPa}$ and elongation at failure of about $11 \%$ in the $\mathrm{T} 6$ condition [21]. According to the tensile testing results, recycled specimens have $R m, R p_{0.2}$, and $P E$ in the range from $248-362 \mathrm{MPa}, 226-326 \mathrm{MPa}$, and $7.1-11.9 \%$, respectively. Tensile testing results for all 20 recycled samples are provided in Table 1. Results for all recycled samples obtained according to the DOE were inserted into computer software 
Design-Expert where ANOVA and RA were carried out resulting in mathematical models for $R m$ and $R p_{0.2}$. According to the regression and variance analysis, $P E$ cannot be described with statistically significant mathematical model. Figure 4 shows engineering stress vs. engineering strain diagrams for 7 randomly selected SSR samples and for conventionally extruded bar in T6 condition. Furthermore, Figure 4 shows the tensile testing result for SSR sample obtained only with direct hot extrusion and afterwards one ECAP pass on room temperature (direct hot extrusion (DE) + ECAP-1p). According to the tensile testing results, mechanical properties $\left(R m, R p_{0.2}\right.$, and $\left.P E\right)$ of the sample obtained with DE and afterwards one ECAP pass on room temperature are significantly lower than those obtained with novel SSR process presented in this work. This clearly indicated that the combination of the ECAP and heat treatment significantly improved the quality of the SSR sample. According to the previous investigation aluminum alloy EN AW 6082 have an aging potential after one ECAP pass. Artificial post-ECAP aging results in an increase in tensile strength, tensile ductility, and tensile work hardening [21]. Furthermore, pre-ECAP aging treatment was found to be slightly more effective in improving the strength than in comparison to post-ECAP aging treatment, while better ductility improvement was achieved by post-ECAP aging treatment. However, effective strengthening by post-ECAP aging treatment is possible at aging temperatures lower than those usually used for artificial aging of EN AW 6082 aluminum alloy [22]. This is attractive for low energy SSR process. Heat treatment used in SSR process should also serve for homogeneous and high quality SSR samples production. Sufficient heat can help improve the interparticle diffusion and chips bonding, while prolonged heating duration to a certain extent can cause better homogeneity of the billet structure in the case of direct recycling of chips [23].

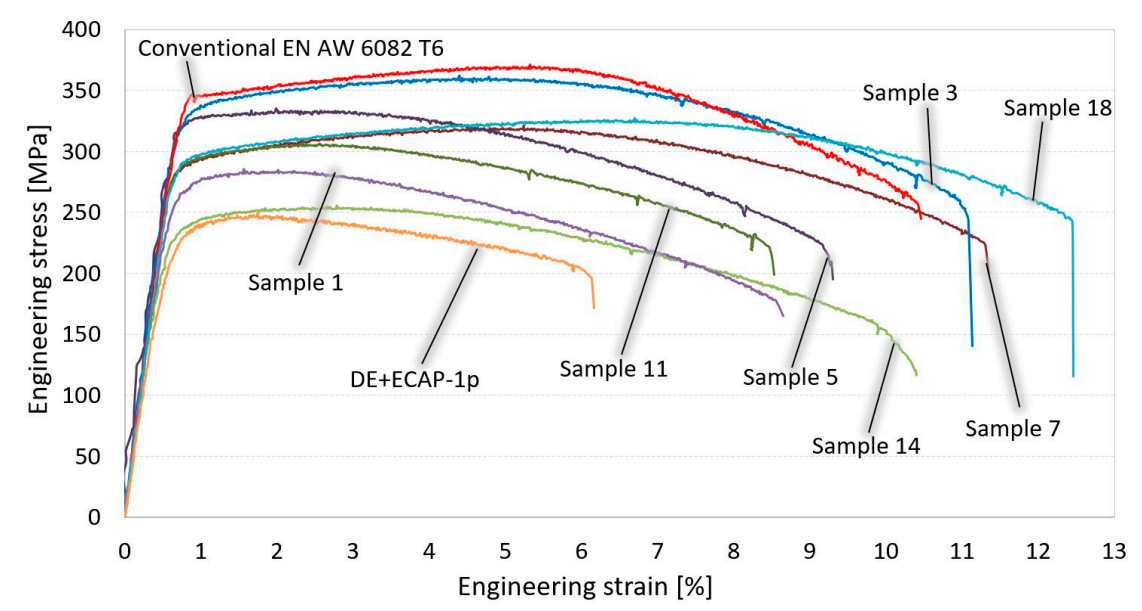

Figure 4. Engineering stress vs. engineering strain diagrams for: one SSR sample obtained with DE and afterwards one ECAP pass; seven randomly selected SSR samples from design of experiments (DOE); conventionally extruded bar in T6 condition.

\subsection{Regression Analysis for Ultimate Tensile Strength}

According to the regression analysis (RA) and variance analysis (ANOVA) quadratic mathematical model was suggested for a description of the influence of heat treatment parameters on the ultimate tensile strength of SSR samples. For better understanding, from now on, $A, B$, and $C$ denote aging temperature $\left({ }^{\circ} \mathrm{C}\right)$, aging time $(\mathrm{h})$, and solid solution time (min), respectively. ANOVA indicates that in this case $A, A B, B C, A^{2}$ were significant model terms. Model quality can be evaluated based on R-Squared, Adj R-Squared, Pred R-Squared, and Adeq Precision values. Quadratic mathematical model obtained with RA had a strong coefficient of determination R-Squared $=0.93$. High R-Squared value indicated that predicted $R m$ values based on the model were in very good agreement with actual experimental values. R-Squared can take values in the range from 0 to 1 and higher R-Squared values causes better regression model fitting of research observations. Furthermore, Adj $R^{2}$ and Pred $R^{2}$ were 0.89 and 0.85 , respectively. Good agreement between $A d j R^{2}$ and Pred $R^{2}$ with a difference no more 
than 0.2 is very important because it prevents overfitting of the model. Finally, Adeq Precision for this model was 17.3. Adeq Precision measures the signal to noise ratio and a ratio greater than 4 is desirable. The quadratic mathematical model in terms of actual factors was adopted as follows:

$$
R m(\mathrm{MPa})=-3.77805+4.95228 A+9.97591 B-0.18768 C-0.11061 A \cdot B+0.040404 B \cdot C-0.016338 A^{2}
$$

Figure 5a shows the graphical presentation of Equation (1) for the constant solid solution time of $60 \mathrm{~min}$. Figure $5 \mathrm{~b}$ shows the graphical presentation of Equation (1) for the constant artificial aging temperature at $100{ }^{\circ} \mathrm{C}$. Surface in Figure 5a confirms conclusions obtained from ANOVA, namely, aging temperature have a pronounced influence on $\mathrm{Rm}$. Increase in aging time slightly increases $R m$ for lower aging temperature $\left(100^{\circ} \mathrm{C}\right)$. However, for higher aging temperature $\left(200^{\circ} \mathrm{C}\right)$, increase in aging time decreases $\mathrm{Rm}$. These results occur probably due to over-aging effect and coarsening of the fine precipitates. Surface in Figure $5 \mathrm{~b}$ indicated that for constant artificial aging temperature at $100{ }^{\circ} \mathrm{C}$ and higher solid solution time (180 $\mathrm{min})$, increase in artificial aging time also increases $\mathrm{Rm}$ value. For lower solid solution time (60 $\mathrm{min}$ ), increase in aging time, increases $R m$ just slightly. However, conclusions from presented diagrams are valid for selected solid solution times and aging temperatures. Authors point readers of this paper to use provided mathematical model in order to get a valid conclusion for the whole range of the heat treatment parameters.
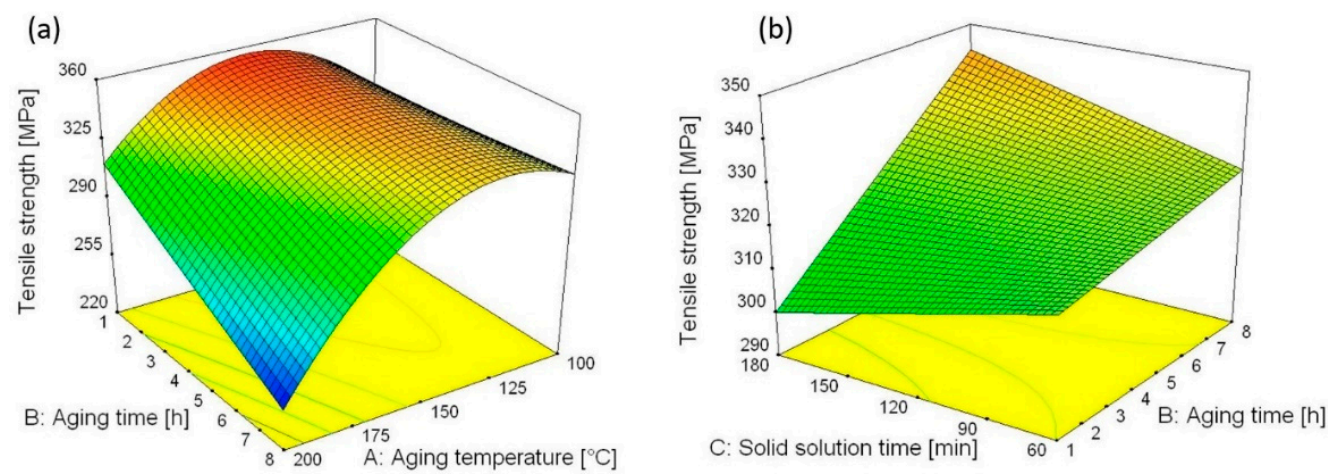

Figure 5. (a) Influence of aging temperature and aging time on tensile strength of SSR samples for constant solid solution time at $60 \mathrm{~min}$ (b) Influence of solid solution time and aging time on tensile strength of SSR samples for constant aging temperature at $100{ }^{\circ} \mathrm{C}$.

\subsection{Regression Analysis for Yield Strength}

According to the RA and ANOVA quadratic mathematical model was suggested for the description of the influence of heat treatment parameters on yield strength of SSR samples. ANOVA indicate that in this case $A, B, A B, B C, A^{2}$ were significant model terms. Quadratic mathematical model obtained with RA had a strong coefficient of determination R-Squared $=0.90$. Furthermore, Adj $\mathrm{R}^{2}$ and Pred $\mathrm{R}^{2}$ were 0.87 and 0.78 , respectively. Finally, Adeq Precision for this model was 15.5. The quadratic mathematical model in terms of actual factors was adopted as follows

$$
R p_{0.2}(\mathrm{MPa})=-7.28300+4.72078 A+8.36101 B-0.27376 C-0.10918 A \cdot B+0.045288 B \cdot C-0.015217 A^{2}
$$

Figure 6a shows the graphical presentation of Equation (2) for the constant solid solution time of $60 \mathrm{~min}$. Figure $6 \mathrm{~b}$ shows the graphical presentation of Equation (2) for the constant artificial aging temperature at $150{ }^{\circ} \mathrm{C}$. Surface in Figure 6a is very similar as for Equation (1). However, according to ANOVA except aging temperature, aging time also have pronounced influence on $R p_{0.2}$ values. According to Figure $6 \mathrm{a}$ increase in aging time slightly increases $R p_{0.2}$ for lower aging temperature $\left(100{ }^{\circ} \mathrm{C}\right)$. However, for higher aging temperature $\left(200{ }^{\circ} \mathrm{C}\right)$, increase in aging time decreases $R p_{0.2}$. Surface in Figure $6 \mathrm{~b}$ indicates that for constant aging temperature at $150{ }^{\circ} \mathrm{C}$, shorter solid solution time $(60 \mathrm{~min})$ and shorter artificial aging time $(1 \mathrm{~h})$ significantly increases $R p_{0.2}$ values. For longer solid 
solution time (180 min), aging time do not have any influence on $R p_{0.2}$ values. However, conclusions from diagrams are valid for selected solid solution time of $60 \mathrm{~min}$ (Figure 6a) and aging temperature at $150{ }^{\circ} \mathrm{C}$ (Figure 6b). Authors point paper readers to use provided mathematical model in order to get valid conclusion for the whole range of the heat treatment parameters. For example, according to the obtained model Equation (2), for constant artificial aging temperature at $100{ }^{\circ} \mathrm{C}$ increase of solid solution and artificial aging time, also increases $R p_{0.2}$ value. Furthermore, for solid solution time of $60 \mathrm{~min}$, increase in aging time do not have any influence on $R p_{0.2}$ values. That is opposite behavior of that described before for artificial aging temperature at $150{ }^{\circ} \mathrm{C}$.
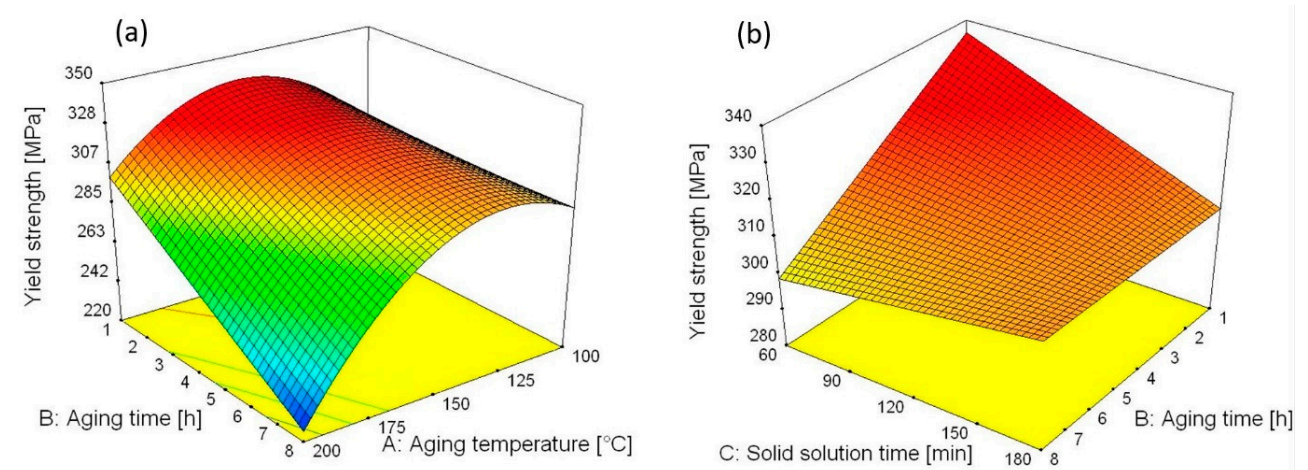

Figure 6. (a) Influence of aging temperature and aging time on yield strength of SSR samples for constant solid solution time at $60 \mathrm{~min}$ (b) Influence of solid solution time and aging time on yield strength of SSR samples for constant aging temperature at $150{ }^{\circ} \mathrm{C}$.

The improved mechanical properties of the SSR samples obtained through the combination of ECAP process with heat treatment were a consequence of complex multifactor phenomena: solid solution strengthening, precipitation hardening, grain refinement and an increase in dislocation density. Usually heat treatment on elevated aging temperature (above $150^{\circ} \mathrm{C}$ for aluminum) after ECAP tends to reduce the strength increase effect of SPD, probably due to partial recrystallization, recovery and release of residual stresses. The highest mechanical strength of heat treatable alloys has been found when the material has been processed in the solid solutionized state followed by post SPD aging at low temperatures, typically about $100^{\circ} \mathrm{C}$ for aluminum [21,32]. However, in this paper highest mechanical properties were found for samples artificially aged on $150{ }^{\circ} \mathrm{C}$ due to the precipitation process in the recycled samples. On the other hand, too high artificial aging temperature or to long artificial aging time probably leads to decrement of the SPD effects and precipitation over-aging which caused $R m$ and $R p_{0.2}$ decrement.

\subsection{Percentage Elongation}

Figure 7 shows percentage elongation values for all 20 SSR samples and for conventionally produced extruded bar in T6 temper condition according to EN 755-2:2016 standard. According to Figure 7 almost all SSR samples (except sample 8 and sample 20) had minimum required percentage elongation proposed by EN 755-2:2016 standard. According to the RA and ANOVA analysis mean value of the all obtained percentage elongation values $\left(P E_{\text {mean }}=9.7 \%\right)$ were suggested to use rather than the mathematical model description of the influence of heat treatment parameters on percentage elongation of SSR samples. This indicated that percentage elongation of the all 20 SSR samples changes in a more complex way (with different heat treatment parameters selection) than is possible to describe with statistically significant mathematical model. However, according to the results, percentage elongations of the SSR samples were significantly increased after the combination of the ECAP with heat treatment in comparison with SSR sample obtained only by direct hot extrusion and one ECAP pass, Figure 4. This is probably because the pre ECAP solid solution treatment results with microporosity reduction 
and improved chip bonding inside SSR samples due to the diffusion phenomena, while post ECAP aging results in a concurrent process involving recovery, partial recrystallization and precipitation.

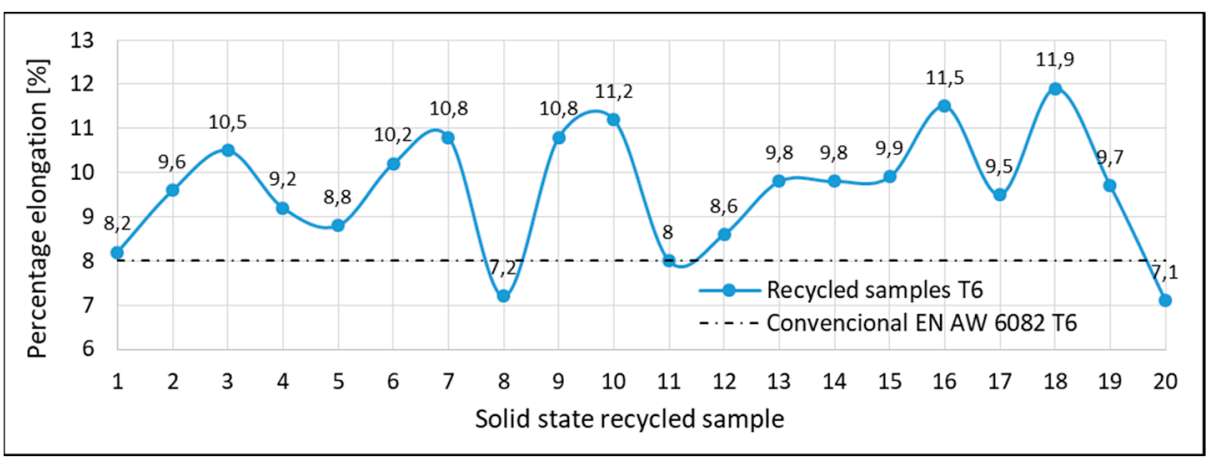

Figure 7. Percentage elongation results for all 20 SSR samples and minimum required percentage elongation proposed by EN 755-2:2016 standard.

The complex influence of the heat treatment parameters on the mechanical properties of the SSR samples ( $R m$ and $R p_{0.2}$ ) once more confirms the necessity for used statistical approach. Obtained mathematical models can be used for $R m$ and $R p_{0.2}$ predictions for the whole range of the used heat treatment parameters. However, an additional experimental plan should provide even more accurate prediction for the narrower range of the heat treatment parameters after optimization of the performed experimental design. Therefore, Design-Expert optimization of the process was also performed. According to the statistical analysis, the influence of heat treatment parameters on percentage elongation cannot be described with statistically significant mathematical model and therefore, mean value of the percentage elongation would be taken as final. For the optimization, maximal values of the $R m$ and $R p_{0.2}$ were set as desirable. Finally, according to the optimization results, maximal values for $R m$ and $R p_{0.2}$ of 356 and $336.6 \mathrm{MPa}$ would be obtained if artificial aging temperature, artificial aging time, and solid solution time were set as $148.2^{\circ} \mathrm{C}, 1 \mathrm{~h}$, and $60 \mathrm{~min}$, respectively.

\subsection{Metallographic Analysis}

The main aim of metallographic analysis was to evaluate the microstructure of the SSR samples and compare it with conventionally produced extruded bar in T6 temper condition. For metallography analysis scanning electron microscope (SEM) and energy-dispersive X-ray spectroscopy (EDX) with technical designation TESCAN VEGA 5136MM were used. Samples were etched in a duration of $8 \mathrm{~s}$ at room temperature with a reagent which consisted of $0.5 \%$ solution of the HF (Hydrofluoric Acid) dissolved in distilled water. Figure 8 shows the microstructure of SSR sample 12 (randomly selected) and conventionally produced EN AW 6082 extruded bar in T6 temper condition. According to Figure 8, the microstructure of the SSR samples is similar as for conventional sample. The microstructure of the recycled sample was very homogeneous and there were not any visible cracks, voids or porosity.

According to the previous microstructure investigation for aluminum alloy EN AW 6082 usually Al-Mg-Si phases (usually characterized as $\mathrm{Al}(\mathrm{FeMn}) \mathrm{Si}$ and $\mathrm{MgSi}$ ) can be distinguished [33,34]. Due to the fact that both samples in this investigation were in $\mathrm{T} 6$ temper condition, $\mathrm{MgSi}$ phase particles were in a form of the fine precipitates and they cannot be clearly distinguished with used magnification and technique, Figure 8. However, SEM + EDX qualitative chemical analysis, performed by elemental mapping of the SSR sample 12 and conventional sample, confirmed that the bright spots were $\mathrm{Al}(\mathrm{FeMn}) \mathrm{Si}$ phase particles. Figure 9 shows qualitative chemical analysis only for recycled sample 12, due to the fact that results for conventional sample were very similar. Visible phase particles were homogeneously dispersed inside both samples. Main alloying element $(\mathrm{Mg})$ was finely dispersed into the structure. Finally, according to the chemical element mapping presented in Figure 9, increased oxide contamination or presence of the oxide layers between aluminum chips were not determined. 


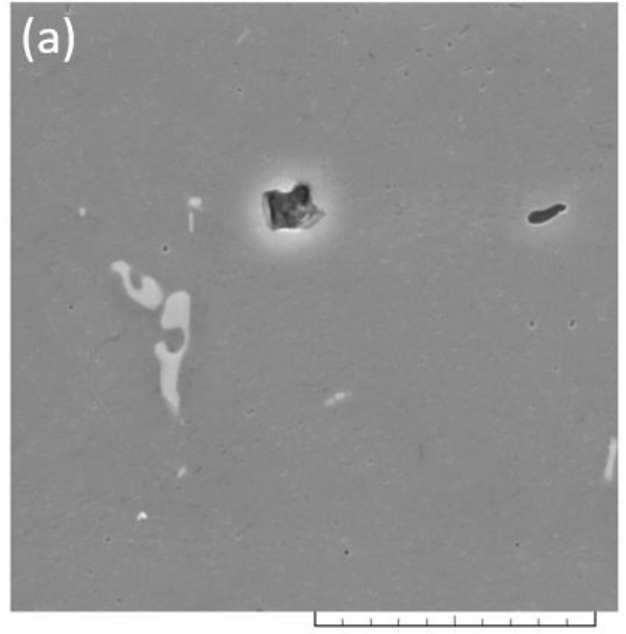

$20 \mu \mathrm{m}$

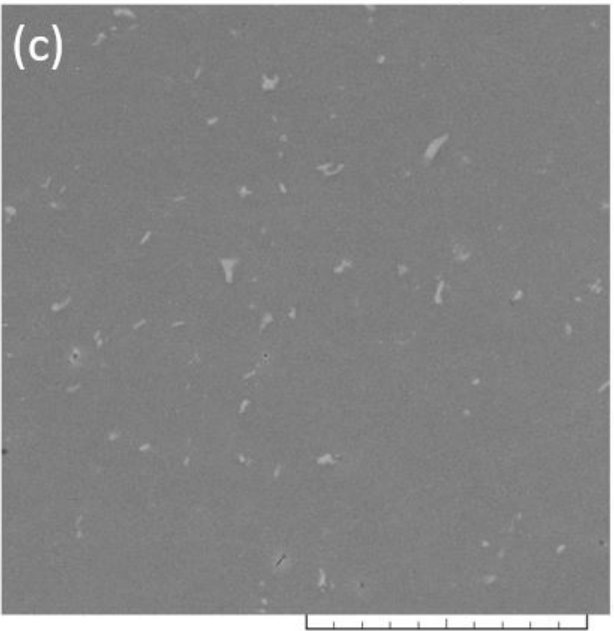

$50 \mu \mathrm{m}$

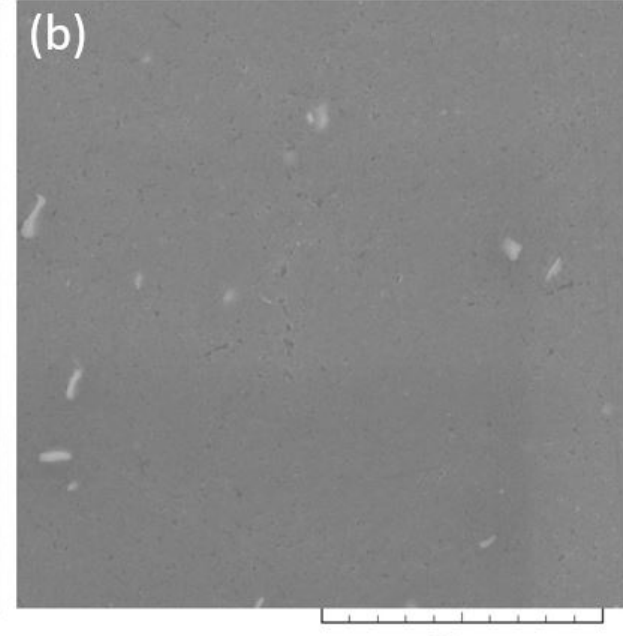

$20 \mu \mathrm{m}$

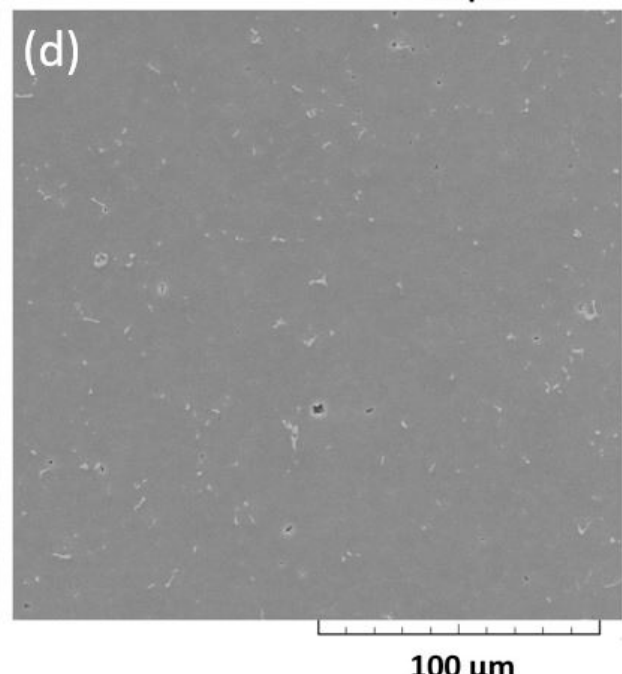

$100 \mu \mathrm{m}$

Figure 8. SEM images for SSR sample 12 and conventional EN AW 6082 extruded bar in T6 temper condition: (a) conventional sample with 5000× magnification; (b) SSR sample 12 with $5000 \times$ magnification; (c) SSR sample 12 with 2000× magnification; (d) conventional sample with $1000 \times$ magnification.
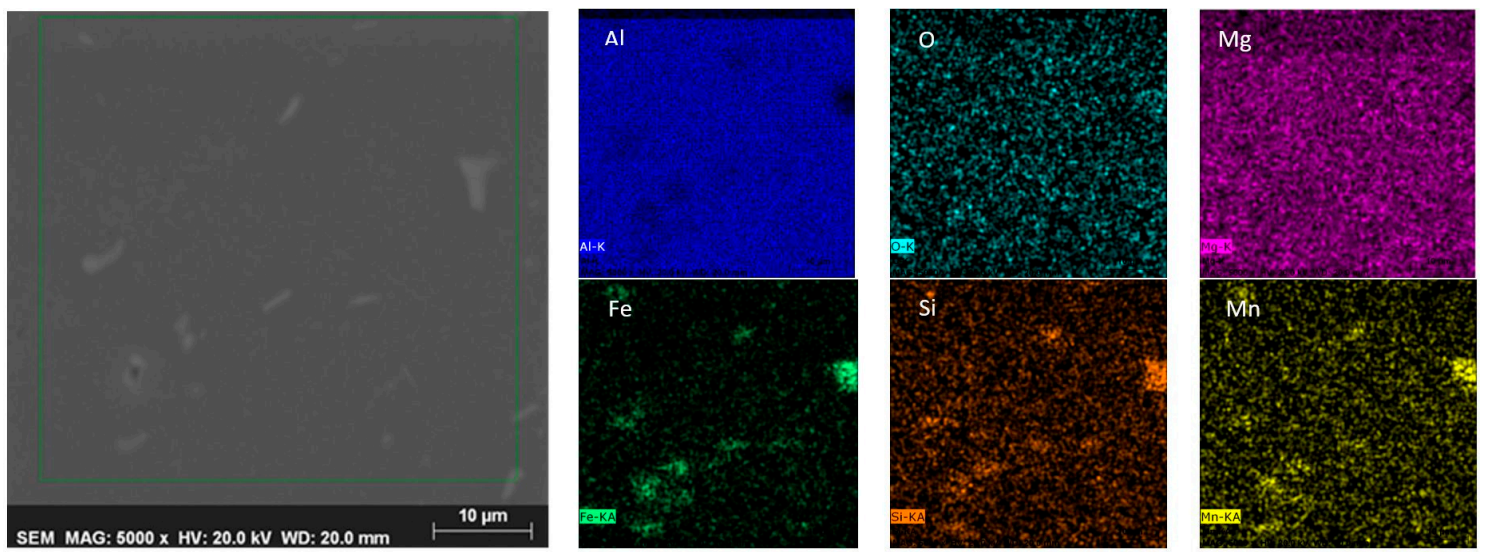

Figure 9. SEM and energy-dispersive X-ray spectroscopy (EDX) element mapping for SSR sample 12. 


\section{Conclusions}

According to the tensile testing results and metallographic analysis high quality SSR samples from EN AW 6082 aluminum alloy chips were obtained utilizing novel SSR process. Recycled samples meet the minimum requirements according to the EN 755-2: 2016 standard for EN AW 6082 extruded bars in $\mathrm{T} 6$ condition.

(1) The lower extrusion ratio could be used for SSR process if afterwards ECAP process in combination with heat treatment will be applied. Combination of the heat treatment and ECAP after DE significantly improved mechanical properties of the SSR samples compared with SSR sample obtained only with DE and afterwards one ECAP pass.

(2) Description and prediction of the influence of heat treatment parameters on $R m$ and $R p_{0.2}$ was successfully performed utilizing statistical analysis approach. Quadratic mathematical models were suggested for description of the influence of heat treatment parameters on $R m$ and $R p_{0.2}$ of SSR samples. Increase in aging time slightly increases $R m$ and $R p_{0.2}$ for lower aging temperature $\left(100^{\circ} \mathrm{C}\right)$. However, for higher aging temperature $\left(200^{\circ} \mathrm{C}\right)$, increase in aging time decreases $\mathrm{Rm}$ and $R p_{0.2}$. For constant artificial aging temperature at $100{ }^{\circ} \mathrm{C}$ and higher solid solution time (180 $\mathrm{min}$ ), increase in artificial aging time, also increases $R m$ value. For lower solid solution time (60 $\mathrm{min}$ ), increase in aging time increases $R m$ just slightly. For constant aging temperature at $150{ }^{\circ} \mathrm{C}$, shorter solid solution time $(60 \mathrm{~min})$ and artificial aging time $(1 \mathrm{~h}) R p_{0.2}$ values significantly increases. According to the statistical analysis, the influence of heat treatment parameters on percentage elongation cannot be described with statistically significant mathematical model and therefore, mean value of the percentage elongation was taken as final $\left(P E_{\text {mean }}=9.7 \%\right)$.

(3) Heat treatment assisted in the improvement of SSR samples quality by the simultaneous interparticle diffusion bonding, recovery and precipitation hardening. However, too high artificial aging temperature or to long artificial aging time leads to decrement of the SPD effects and precipitation over-aging which caused mechanical properties decrement. Finally, according to the optimization results maximal values for $R m$ and $R p_{0.2}$ of 356 and $336.6 \mathrm{MPa}$ would be obtained if artificial aging temperature, artificial aging time, and solid solution time were set as $148.2^{\circ} \mathrm{C}, 1 \mathrm{~h}$, and $60 \mathrm{~min}$, respectively.

(4) According to the SEM + EDX analysis microstructure of the recycled samples was very homogeneous and there were not any visible cracks, voids or porosity. Qualitative chemical analysis performed by elemental mapping showed that visible intermetallic phase particles were consisted of the same elements for the SSR samples and for conventionally obtained sample.

Finally, further investigation directions for SSR should be based on fatigue properties determination for the SSR samples. Metal material fatigue strongly depends on microstructure imperfections and its determination should provide fulfilled insight into the quality of the SSR samples.

Author Contributions: J.K. conceived, designed and performed the experiments; J.K. and B.L. designed D-Optimal plan of the experiments; J.K. and I.D. performed the statistical analysis and paper writing; F.K. and J.K. performed metallographic analysis; I.D. and B.L. peer reviewed paper writing and editing; B.L. was responsible for experiments supervision; B.L. were responsible for funding acquisition; All authors reviewed the final paper.

Funding: This research received no external funding. APC was funded by Faculty of Electrical Engineering, Mechanical Engineering and Naval Architecture, Split.

Conflicts of Interest: The authors declare no conflict of interest.

\section{References}

1. Stacey, M. Aluminium Recyclability and Recycling; Towards Sustainable Cities; Cwningen Press, International Aluminium Institute: Nottingham/Llundain, UK, 2015. Available online: http://www.world-aluminium.org/ media/filer_public/2016/10/03/tsc_report2_arr_72dpi_release_locked_1016.pdf (accessed on 15 May 2019). 
2. International Aluminium Institute. Global Aluminium Recycling: A Cornerstone of Sustainable Development. Available online: http://world-aluminium.org/media/filer_public/2013/01/15/fl0000181.pdf (accessed on 15 May 2019).

3. Cullen, J.M.; Allwood, J.M. Mapping the Global Flow of Aluminum: From Liquid Aluminum to End-Use Goods. Environ. Sci. Technol. 2013, 47, 3057-3064. [CrossRef] [PubMed]

4. Allwood, J.M.; Cullen, J.M. Sustainable Materials with Both Eyes Open; UIT Cambridge Ltd.: Cambridge, UK, 2012.

5. Duflou, J.R.; Tekkaya, A.E.; Haase, M.; Welo, T.; Vanmeensel, K.; Kellens, K.; Dewulf, W.; Paraskevas, D. Environmental assessment of solid state recycling routes for aluminum alloys: Can solid state processes significantly reduce the environmental impact of aluminum recycling? CIRP Ann. Manuf. Technol. 2015, 64, 37-40. [CrossRef]

6. Gronostajski, J.; Matuszak, A. The recycling of metals by plastic deformation: An example of recycling of aluminum and its alloy chips. J. Mater. Process. Technol. 1999, 92, 35-41. [CrossRef]

7. Tekkaya, A.E.; Schikorra, M.; Becker, D.; Biermann, D.; Hammer, N.; Pantke, K. Hot profile extrusion of AA-6060 aluminum chips. J. Mater. Process. Technol. 2009, 209, 3343-3350. [CrossRef]

8. Allwood, J.M.; Cullen, J.M.; Cooper, D.R.; Milford, R.L.; Patel, A.C.H.; Carruth, M.A.; McBrien, M. Conserving Our Metal Energy: Avoiding Melting Steel and Aluminum Scrap to Save Energy and Carbon. WellMet2050 Report, University of Cambridge. Available online: https:/www.uselessgroup.org/files/wellmet2050conserving-our-metal-energy-sept-2010-web.pdf (accessed on 19 July 2018).

9. Paraskevas, D.; Kellens, K.; Renaldi, W.D.; Duflou, J.R. 4.10 Resource Efficiency in Manufacturing: Identifying Low Impact Paths. In Proceedings of the 10th Global Conference on Sustainable Manufacturing (GCSM2012), Instabul, Turkey, 31 October-2 November 2012; pp. 271-276.

10. Shamsudin, S.; Lajis, M.A.; Zhong, Z.W. Solid-state recycling of light metals: A review. Adv. Mech. Eng. 2016, 8, 1-23. [CrossRef]

11. Vrelinden, B. Severe plastic deformation of metals. Metal. J. Metall. 2003, 165-182. [CrossRef]

12. Cui, J.; Roven, H.J. Recycling of automotive aluminum. Trans. Nonferrous Met. Soc. China 2010, 20, $2057-2063$. [CrossRef]

13. Luo, P.; McDonald, D.T.; Zhu, S.M.; Palanisamy, S.; Dargusch, M.S.; Xia, K. Analysis of microstructure and strenghtening in pure titanium recycled from machining chips by equal channel angular pressing using electron backscatter diffraction. Mater. Sci. Eng. A 2012, 538, 252-258. [CrossRef]

14. Cui, J.R.; Guo, W.; Roven, H.J.; Wang, Q.D.; Chen, Y.J.; Peng, T. Recycling of Aluminum Scrap by Severe Plastic Deformation. Mater. Sci. Forum 2011, 667, 1177-1182. [CrossRef]

15. Mohamed, I.A.E.A.; Eun, Y.Y.; Hyoung, S.K. Recycling of AlSi8Cu3 alloy chips via high pressure torsion. Mater. Sci. Eng. A 2013, 560, 121-128. [CrossRef]

16. Tang, W.; Reynolds, A.P. Production of wire via friction extrusion of aluminum alloy machining chips. J. Mater. Process. Technol. 2010, 210, 2231-2237. [CrossRef]

17. Li, X.; Baffari, D.; Reynolds, A.P. Friction stir consolidation of aluminum machining chips. Int. J. Adv. Manuf. Technol. 2018, 94, 2031-2042. [CrossRef]

18. Ying, T.; Zheng, M.; Hu, X.; Wu, K. Recycling of AZ91 Mg alloy through consolidation of machined chips by extrusion and ECAP. Trans. Nonferrous Met. Soc. China 2010, 20, 604-607. [CrossRef]

19. Krolo, J.; Lela, B.; Švagelj, Z.; Jozić, S. Adaptive neuro-fuzzy and regression models for predicting microhardness and electrical conductivity of solid-state recycled EN AW 6082. Int. J. Adv. Manuf. Technol. 2019, 100, 2981-2993. [CrossRef]

20. Hasse, M.; Ben Khalifa, N.; Tekkaya, A.E.; Misiolek, W.Z. Improving mechanical properties of chip-based aluminum extrudates by integrated extrusion and equal channel angular pressing (iECAP). Mater. Sci. Eng. A 2012, 539, 194-204. [CrossRef]

21. Werenskiold, J.C. Equal Channel Angular Pressing (ECAP) of AA6082: Mechanical Properties, Texture and Microstructural Development. Ph.D. Thesis, Norwegian University of Science and Technology, Trondheim, Norway, 2004.

22. Dadbakhsha, S.; Karimi Taheria, A.; Smith, C.W. Strengthening study on $6082 \mathrm{Al}$ alloy after combination of aging treatment and ECAP process. Mater. Sci. Eng. A 2010, 527, 4758-4766. [CrossRef] 
23. Shamsudin, S.; Zhong, Z.W.; Rahim, S.N.; Lajis, M.A. The influence of temperature and preheating time in extrudate quality of solid-state recycled aluminum. Int. J. Adv. Manuf. Technol. 2017, 90, 2631-2643. [CrossRef]

24. Lela, B.; Krolo, J.; Jozić, S. Mathematical modeling of solid-state recycling of aluminum chips. Int. J. Adv. Manuf. Technol. 2016, 87, 1125-1136. [CrossRef]

25. Ansari, M.A.; Behnagh, R.A.; Narvan, M.; Naeini, E.S.; Givi, M.K.B.; Ding, H. Optimization of Friction Stir Extrusion (FSE) Parameters through Taguchi Technique. Trans. Indian Inst. Met. 2016, 69, 1351-1357. [CrossRef]

26. Khamis, S.S.; Lajis, M.A.; Albert, R.A.O. A Sustainable Direct Recycling of Aluminum Chip (AA6061) in Hot Press Forging Employing Response Surface Methodology. Procedia CIRP 2015, 26, 477-481. [CrossRef]

27. Kurama, E.; Ozcelik, B.; Bayramoglu, M.; Demirbas, E.; Simsek, B.T. Optimization of cutting fluids and cutting parameters during end milling by using D-optimal design of experiments. J. Clean. Prod. 2013, 42, 159-166. [CrossRef]

28. Behrens, B.A.; Frischkorn, C.; Bonhage, M. Reprocessing of AW2007, AW6082 and AW7075 aluminium chips by using sintering and forging operations. Prod. Eng. 2014, 8, 443-451. [CrossRef]

29. Mindivan, H.; Cimenoglu, H.; Kayali, E.S. Production of the composite from $6082 \mathrm{Al}$ alloy chips and fly ash particles by hot pressing. In Proceedings of the Minerals, Metals \& Materials Society (TMS) Annual Meeting 2009, San Francisco, CA, USA, 15-19 February 2009.

30. Paraskevas, D. Complex deformation routes for direct recycling aluminium alloy scrap via industrial hot extrusion. In Proceedings of the 21st International ESAFORM Conference on Material Forming, Palermo, Italy, 23-25 April 2018. [CrossRef]

31. Güley, V.; Khalifa, N.B.; Tekkaya, A.E. The effect of extrusion ratio and material flow on the mechanical properties of aluminum profiles solid state recycled from 6060 aluminum alloy chips. In Proceedings of the 14th International ESAFORM Conference on Material Forming, Belfast, Northern Ireland, 27-29 April 2011; pp. 1609-1614. [CrossRef]

32. Tańskia, T.; Snopińskia, P.; Prusikc, K.; Srokaa, M. The effects of room temperature ECAP and subsequent aging on the structure and properties of the Al-3\%Mg aluminium alloy. Mater. Charact. 2017, 133, 185-195. [CrossRef]

33. Tercelj, M.; Fazarinc, M.; Kugler, G.; Perus, I. Influence of the chemical composition and process parameters on the mechanical properties of an extruded aluminium alloy for highly loaded structural parts. Constr. Build. Mater. 2013, 44, 781-791. [CrossRef]

34. Jadhav, S.; Singh, R.; Vinayak, P.; Mane, S. Influence of Heat Treatment on Mechanical Properties and Microstructure of EN AW 6082 Aluminum alloy. In Proceedings of the 8th International Conference on Mechanical and Aerospace Engineering, Prague, Czech Republic, 22-25 July 2017; pp. 184-187. [CrossRef] 